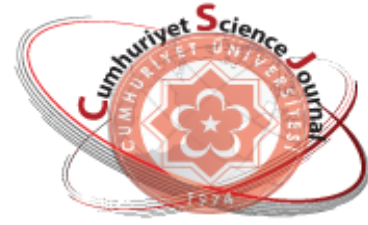

e-ISSN: $2587-246 X$

ISSN: $2587-2680$

\section{Cumburiyet Seionce Journal $\operatorname{csj}$}

Cumhuriyet Sci. J., Vol.38-3 (2017) 419-426

\author{
Aster Uydu Görüntüleri ile Hidrotermal Alterasyon Alanlarının \\ Belirlenmesi: Ağmaşat Yaylası-Zara (Sivas) / Türkiye Örneği \\ Oktay CANBAZ ${ }^{1 *}$, Önder GÜRSOY', Ahmet GÖKCE ${ }^{1}$ \\ ${ }^{1}$ Cumhuriyet Üniversitesi, Jeoloji Mühendisliği Bölümü, 58140, Sivas, TÜRKIYYE \\ ${ }^{2}$ Cumhuriyet Üniversitesi, Geomatik Mühendisliği Bölümü, 58140, Sivas, TÜRKIYE
}

Received: 08.05.2017; Accepted: 20.06.2017

http://dx.doi.org/10.17776/csj.340473

\begin{abstract}
Özet: Hidrotermal alterasyon alanlarının tespiti, maden arama faaliyetlerinin ilk aşamalarından bir tanesi olup özellikle porfiri tip zenginleşmelerin keşfinde önemli bir adımı oluşturmaktadır. Önceleri arazi çalışmaları ve gözlemlerle tespit edilebilen bu tür alanlar artık günümüzde gelişen teknoloji ile birlikte uydulardan elde edilen görüntüler üzerinde yapılan işlemlerle tespit edilebilmektedir. Bu çalışmada Sivas ilinin Zara ilçesinin kuzeyinde Ağmaşat Yaylası'nda belirlenen hidrotermal alterasyon alanlarının ve çevre jeolojik birimlerinin sınırları ASTER uydusu SWIR görüntüleri ile belirlenmeye çalışılmıştır. Uygulanan dekorelasyon gerilmesi ve ana bileşenler dönüşümü metodları ile elde edilen veriler, arazi çalışmaları sırasında hazırlanan jeoloji haritası ile yükssek oranda örtüştüğü belirlenmiştir. Bu veriler ışığında tespit edilebilecek yeni alterasyon alanları potansiyel maden sahası olarak değerlendirilebilecektir.
\end{abstract}

Anahtar Kelimeler: Hidrotermal Alterasyon, Zara-Sivas, Eosen Volkanitleri, Dekorelasyon Gerilmesi, Ana Bileşenler Dönüşümü

\title{
Determination of Hydrothermal Alteration Areas by Aster Satellite Images: Ağmaşat Plato-Zara (Sivas) / Turkey Sample
}

\begin{abstract}
Determination of hydrothermal alteration areas is one of the first stage methodes used in mineral exploration studies, particularly of porphyry type mineralizations. These studies were only possible by field investigations in the past, but now, they can be easily detected with images from satellites, in accordance with the developing technology. In this study, contacts between geological units and the border of the hydrothermal alteration zones were determined with SWIR images of ASTER in Ağmaşat Plato, located in the north of Zara district of Sivas province. Decorrelation stretching and principal component analysis were carried out on the SWIR images. The obtained results highly coincide with the geological map which was prepared during the field studies. These results will lead to the discovery of new potential fields.
\end{abstract}

Keywords: Hydrothermal Alteration, Zara-Sivas, Eocene Volcanic Rocks, Decorelation Stretching, Principal Component Analysis 


\section{GİRIŞ}

Maden arama faaliyetlerinin önemli aşamalarından bir tanesi olan hidrotermal alterasyonlar, cevher oluşturucu hidrotermal suların etkisiyle yan kayaçta meydana gelen mineralojik-kimyasal ve fiziksel değişimleri kapsamaktadır. Yüzeye çıkmamış cevherleşmelerin keşfinde bu tür oluşumlar araştırıcılar için en önemli ipuçlarını taşımaktadırlar. Arazi sırasında ya da uydu görüntüleri yardımıyla bu tür alanların tespiti yapılabilmektedir. Son y1llarda hidrotermal alterasyon alanlarının haritalanmasında, arazi ve laboratuar çalışmalarının yanı sıra uzaktan algılama en önemli yöntemlerden biri haline gelmiştir. Jeologlar, özellikle porfiri yatakların keşfinde önemli bir yere sahip olan hidrotermal alterasyon minerallerinin haritalanmasında uzaktan algılama yöntemlerini kullanmaktadırlar [1-4]. Bu tür çalışmalar kapsamında uzaktan algılama yöntemlerinin uygulandığı en önemli uydu görüntülerinden bir tanesini ASTER (Advanced Spaceborne Thermal Emission and Reflection Radiometer) multispektral görüntüleme sensörü oluşturmaktadır. ASTER yerkürenin yüzeyinden yansıyan ve yayılan elektromanyetik enerjiyi 14 spektral bandı içerisinde kayıt eder. Bu bantlar 3 adet VNIR (Görünür bölge yakın kızılötesi radyometre), 6 adet SWIR (Yakın dalga boyu kızılötesi) ve 5 adet TIR (Termal kızılötesi radyometre) şeklindedir. Bölgesel haritalama da kullanışlı olan bu yöntem, SWIR bant aralığında $\mathrm{Al}-\mathrm{OH}, \mathrm{Fe}, \mathrm{Mg}-\mathrm{OH}, \mathrm{Si}-\mathrm{O}-\mathrm{H}$ ve $\mathrm{CO}_{3}$ gibi hidrotermal alterasyon minerallerinin belirlenmesi ve tanımlanması aşamasında da kullanılmaktadır [5,6,7,8,9]. Önceki çalışmalar, alunit, kaolinit, karbonat, dolomit, klorit, talk ve muskovit gibi hidrotermal alterasyon minerallerinin ASTER SWIR bantları ile belirlenebildiğini göstermektedir $[10-15,1]$. Ayrica ASTER VNIR ve TIR bantları, karbonat ve silikatların minerallerin haritalanmasında ve toprak içindeki oksit minerallerinin ve bitkilerin tanımlanmasında kullanılmaktadır [16-18].

İnceleme alanı, Orta Anadolu kuzeydoğusunda ki Eosen yaşlı volkanitlerin içerisinde yer alan Ağmaşat Yaylası'nda (Zara-Sivas), Kösedağ Plütonu ile Karataş Volkanitleri sınırına yakın bir alanda yoğun hidrotermal killeşme içeren bir bölgedir. $\mathrm{Bu}$ yoğun alterasyona uğramış sahanın inceleme alanı olarak belirlenmesinde geçmişte $\mathrm{Pb}-\mathrm{Zn}$ damarlarının işletilmiş olması [19] ve günümüzde de MTA (Maden Tetkik ve Arama Müdürlüğü) tarafindan altın arama faaliyetlerinin gerçekleştirilmesi etkili olmuştur. Çalışma kapsamında bu killeşme alanlarının, arazi çalışmaları ve uzaktan algılama yöntemleri ile belirlenmesi amaçlanmıştır. ASTER uydu verilerine, görüntü zenginleştirme yöntemlerinden dekorelasyon gerilmesi ve ana bileşenler dönüşümü uygulanarak, uydu görüntülerinin yorumlanabilirliği artırılmıştır. Görüntü zenginleştirme işlemi uygulanmış uydu görüntü verileri analiz edilerek hidrotermal alterasyon bölgelerinin belirlenmesi amaçlanmıştır. Çalışmadan elde edilecek verilerin benzer potansiyel sahaların belirlenmesine yardımc olacağı düşünülmektedir.

\section{BÖLGESEL JEOLOJİ}

İnceleme alanı, Sivas'in kuzeydoğusunda yer alan İzmir-Ankara-Erzincan (lAE) sutur zonunun kuzeyindeki Avrasya Levhası (EP) ile TorosAnatolid platformu (TAP) arasındaki çarpışma bölgesinin çevresel bölümünde, doğu-orta pontidlerin içerisinde ki sutur zonda yer almaktadır [20]. Ayrıca bu zon Çamlıbel-Kızıldağ Ofiyolitik Melanjını içermektedir. Bu çarpışma zonunun kuzey ve kuzeybatı sinırında Sakarya Zonuna ait Tokat masifi yer alırken güney sınırında ise Kırşehir Bloğu Metamorfikleri (Orta Anadolu Kristalin Kompleksi) yer almaktadır. Ofiyolitik kayaçların, Tetis okyanusun kapanması sırasında yüzeylediği ve bu okyanusun kuzey kolunda oluştuğu, bu dönemde, EP ve TAP çarpıştığı Tokat Masifi ve Kırşehir Bloğu'na ait premetamorfik kayaçlarının metamorfizma geçirdiği görüşü genel olarak kabul görmektedir. Kösedağ Siyeniti ve volkanik kayaçları Paleosen-Eosen döneminde bu ofiyolitik kayaçlar içerisine yerleşmişlerdir. Genç sedimanter ve volkanik kayaçlar ise bu birimleri uyumsuz olarak örtmektedirler (Şekil 1). 


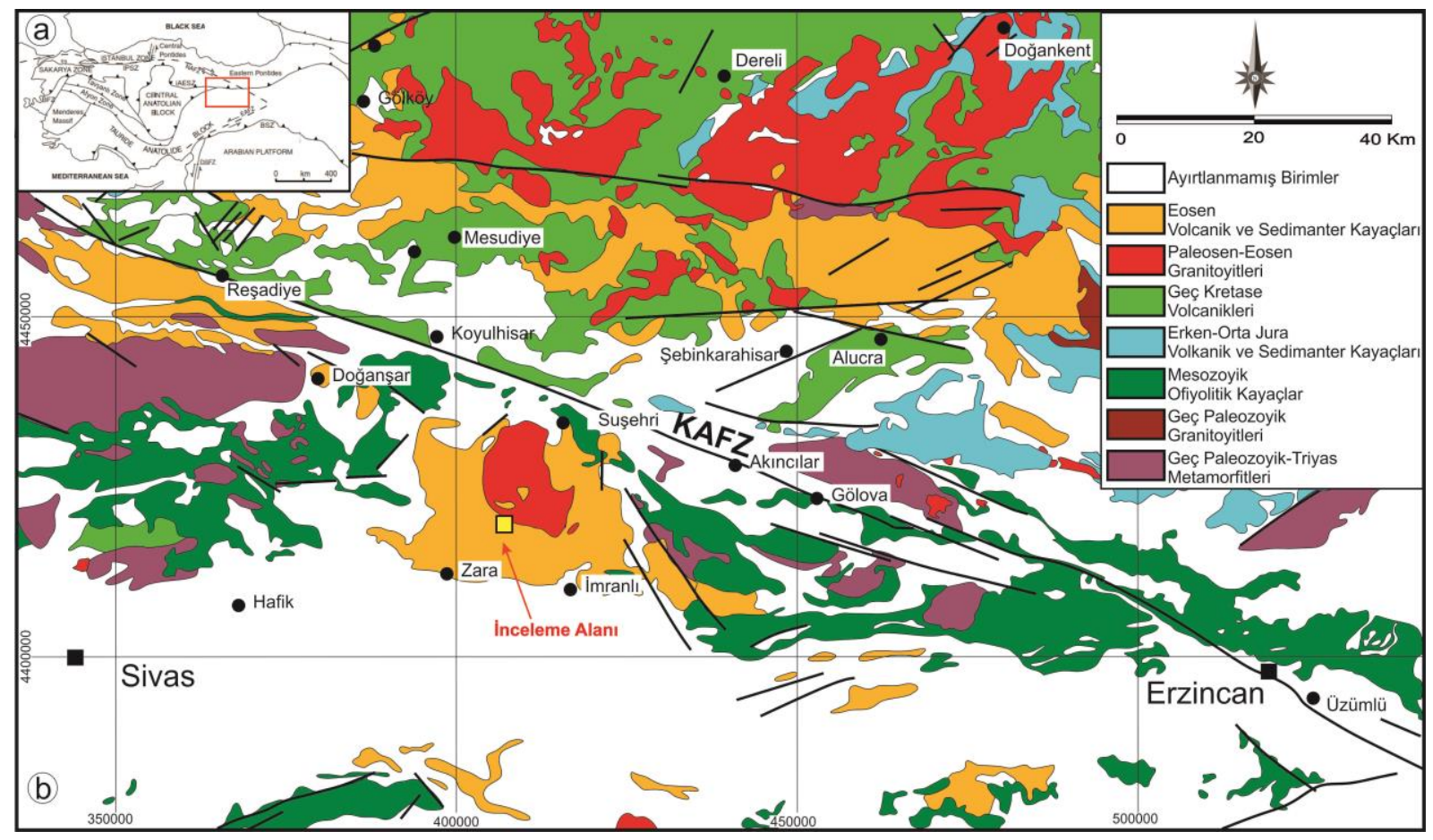

Şekil 1. a) Türkiye tektonik haritası [21]. b) İnceleme alanı bölgesel jeoloji haritası (Maden Tetkik ve Arama Müdürlüğüne ait haritalardan revize edilmiştir).

Çalışma bölgesinin jeolojisi ile ilgili yapılan diğer bir görüş ise; inceleme alanı, yüksek ve düşük dereceli metamorfikler, Geç Karbonifer yaşlı metamorfizma geçirmemiş granitik intrüzyonlar, Geç Triyas-Erken Jura Alaskan tipi mafikultramafik intrüzyonlar [22,23], Geç Kretase şoşonitik-ultrapotasik kayaçlar [22], Geç PaleosenErken Eosen adakitik kayaçlar [24,25,26,27,28] ve Eosen bazaltik-andezitik volkanikler ve granitik intrüzyonlar [29] içeren Pontidlerin güney zonunda yer almaktadır.

Eosen yaşlı Kösedağ Plütonunun siyenitik ve kuvars siyenitik bileşimli olduğunu, K-Feldispat megakristalleri içeren faneritik ve porfirik dokulu olduğunu, plajiyoklaz, klinopiroksen, amfibol, biyotit ve kuvars içeren bir matrikse sahip olduğu belirtilmiştir [20]. Eosen Yaşlı Karataş Volkanitleri, bazalt, trakibazalt, trakiandezitten andezite değişen bileşime sahip olup [30] KFeldispat ve piroksen megakristalleri içeren porfirik dokuya sahiptir. Daha genç sedimanter ve volkanik kayaçlar ise bu birimleri uyumsuz olarak örtmektedir.

\section{HIDROTERMAL ALTERASYON}

İnceleme alanı içerisinde Karataş Volkanitleri üzerinde yoğun hidrotermal alterasyon gelişmiştir (Şekil 2). İnceleme alanından toplanan temsili örneklerin petrografik incelemelerinde yoğun killeşmenin yanısıra serizitleşme ve kloritleşme belirlenmiştir. Ayrıca alünit, kuvars ve pirit damarcıklarının yanı sıra hematit ve limonit oluşumları da gözlenmiştir. Genel olarak bu alterasyonların büyük bir kısmını hidrotermal çözeltiler oluşturmasına rağmen, yüzeyde ki örneklerin alterasyonuna atmosferik koşullarında katkı sağladığı düşünülmektedir. 


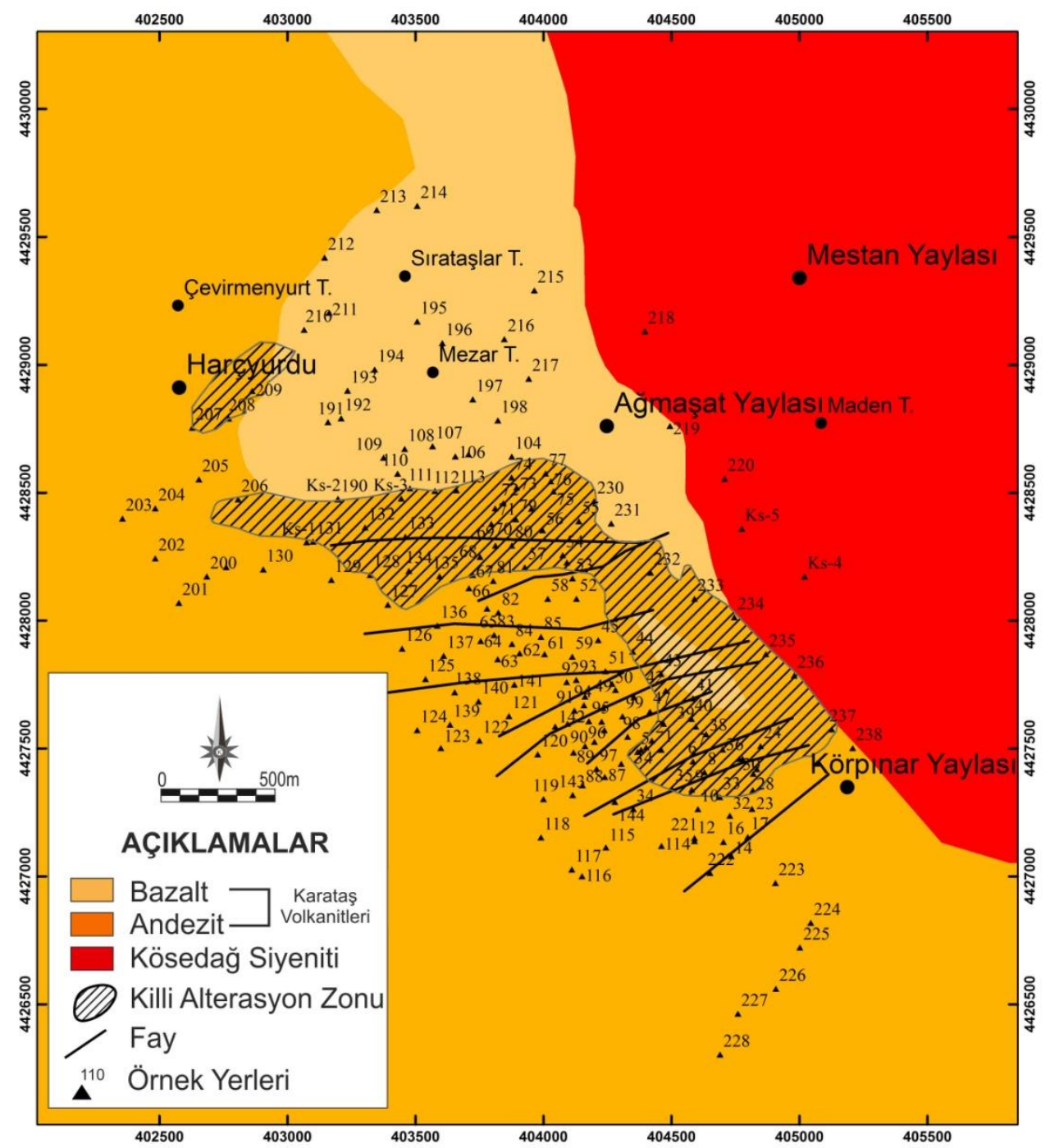

Şekil 2. İnceleme alanı yakın çevresinin jeoloji haritası.

\section{MATERYAL ve METOD}

Arazi çalışmaları kapsamında, inceleme alanında yüzeyleyen kayaçlardan hem taze hem de altere kısımlarını temsil edecek şekilde, yaklaşık 15-20m derinlik ve aralıklarla sistematik olarak 450 adet sondaj ve yüzey örneği toplanmıştır. Bu örneklerin makroskopik incelemeleri saha çalışmalarında, petrografik incelemeleri ise labaratuvar ortamında üstten aydınlatmalı polarizan mikroskop ile gerçekleştirilmiştir. Arazi çalışmaları sırasında Maden Tetkik ve Arama Genele Müdürlüğü (MTA) tarafından hazırlanan 1/100.000 ölçekli jeoloji haritası ve 1/25.000 ölçekli topografik haritaları kullanılarak inceleme alanının 1/10.000 ölçekli jeoloji haritası hazırlanmıştır (Şekil 2).

Bu çalışmada kullanılan ASTER SWIR uydu verilerine, görüntülerin kullanılabilirliğini artırmak için çapraz karışma (crosstalk) düzeltmesi [31], radyans kalibrasyonu ve atmosferik düzeltme ile radyansdan reflektansa dönüştürme işlemleri sırasıyla uygulanmıştır. Görüntü zenginleştirme ve korelasyon gidermede kullanılan ana bileşenler dönüşümü, ve dekorelasyon gerilmesi işlemleri litolojik farklılıkları ortaya çıkarmak için kullanılmıştır. 


\subsection{Ana Bileșenler Dönüşümü}

Ana bileşenler dönüşümü, bantlar arasındaki yüksek korelasyonu azaltarak, görüntülerin görsel yorumlanabilirliğini artırmak için görüntüdeki toplam bilgiyi mevcut bant sayısından daha az sayıda yeni bileşende toplamaktadır [32]. Bu çalışmada 6 bant içeren SWIR görüntülerine uygulanan dönüşüm sonrasinda 1., 2. ve 3 . bileşenleri kullanılarak elde edilen görüntüde, killeşme gösteren alanların kırmızımsı tonlarında, Kösedağ Siyeniti yeşil ve Karataş Volkanitlerinin mavi tonda renklerle birbirinden ayrıldığ 1 görülmektedir (Şekil 3).

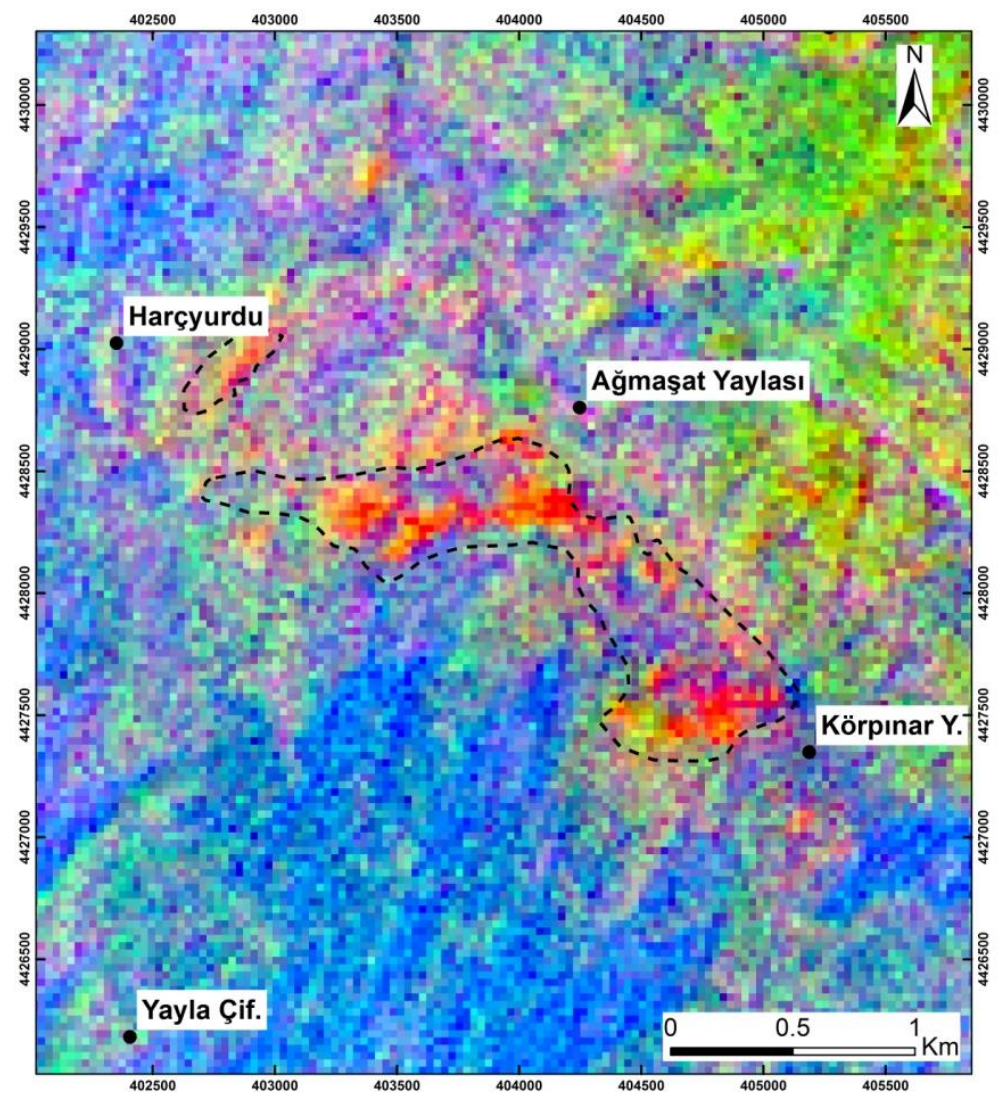

Şekil 3. Ana bileşenler dönüşümü (R:SWIR 3, G: SWIR 5, B:SWIR 6). Kösedağ Siyeniti (yeşil tonlarında), Karataş Volkanitleri (mavi tonlarında) ve killeşme alanları (kırmızı tonlarında).

\subsection{Dekorelasyon Gerilmesi}

Ana bileşenler yönteminde olduğu gibi dekorelasyon gerilmesi, yüksek korelasyona sahip çok bantlı görüntülerde renk zenginleştirmesi yapan bir yöntemdir. Renklerde meydana gelen yoğunlaşma ile görsel yorumlanabilirliğin artırılmasını sağlamaktadır [33, 34]. Bu çalışma kapsaminda, ASTER uydusunun SWIR bantlarından en düşük korelasyona sahip 9-7-4 nolu bantlarına dekorelasyon gerilmesi uygulanmıştır. Elde edilen görüntüde açık mavi renk tonlarının killeşme alanlarını, menekşe renkli kısımların Kösedağ siyeniti ve sarımsı renkli alanların ise Karataş Volkanitlerini gösterdiği belirlenmiştir (Şekil 4). 


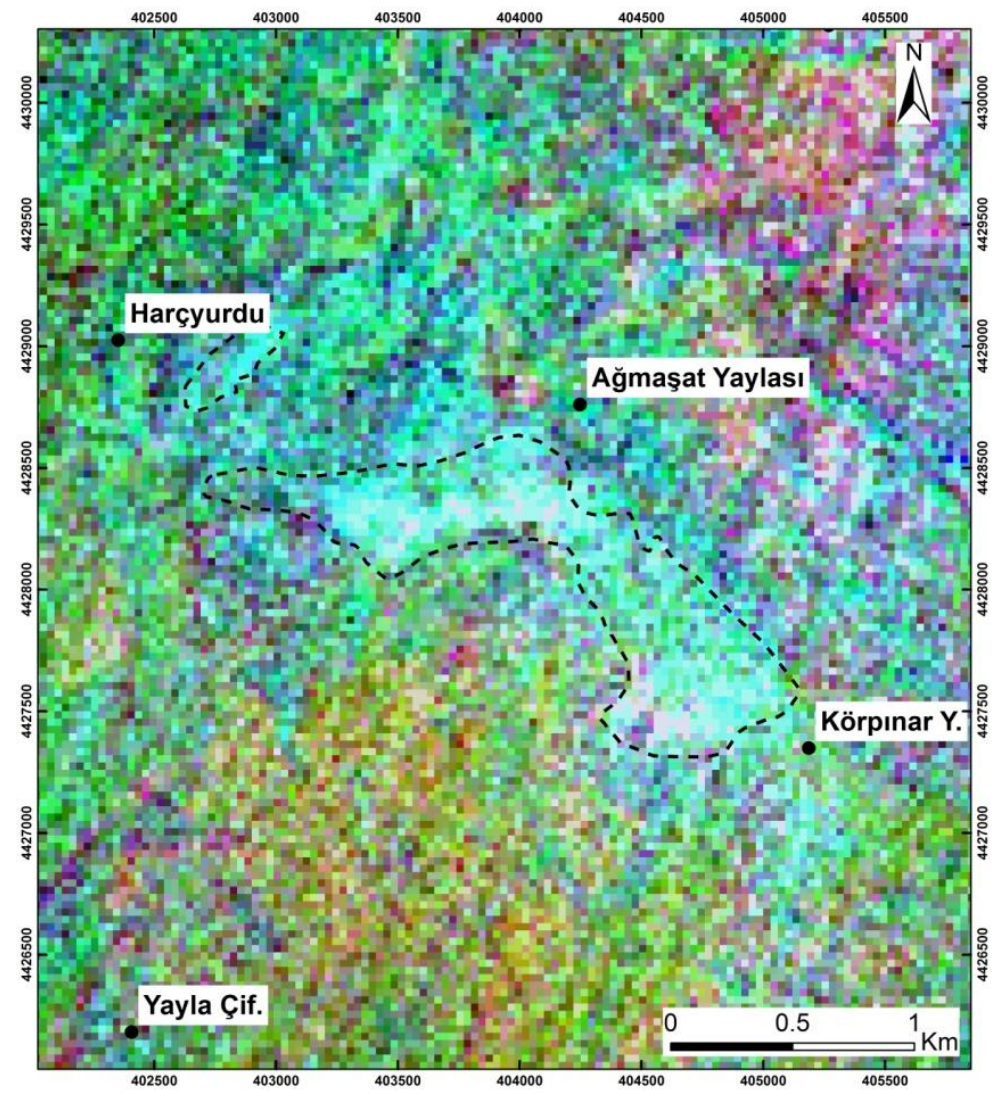

Şekil 4. Dekorelasyon gerilmesi (R:SWIR 9, G: SWIR 7, B:SWIR 4). Kösedağ Siyeniti (menekşe tonlarında), Karataş volkanitleri (sarı tonlarında) ve killeşme alanları (açık mavi tonlarında).

\section{SONUÇLAR}

Bu çalışma, Orta Anadolu Kuzeybatısında, Sivas ilinin Zara ilçesinin kuzeyinde yeralan Ağmaşat Yaylası civarında yüzlek veren Eosen Volkanitleri içerisinde gelişmiş hidrotermal alterasyon gösteren alanda gerçekleştirilmiştir. Bitki örtüsünü bakımından fakir ve alterasyon bakımından yoğun olan bu bölgenin altın için potansiyel bir saha özelliği taşıması inceleme sahası olarak belirlenmesinde önemli rol oynamıştır.

Hidrotermal alterasyonlar, henüz yüzeylememiş potansiyel maden yataklarının yeryüzündeki işaretleridir. $\mathrm{Bu}$ tür sahaların tespiti, gizliliğini koruyan bu maden yatakların bulunmasında ilk adımlardan birini oluşturmaktadır. Son y1llarda önemli bir yere sahip olan uzaktan algılama yöntemleri, bu sahaların tespitinde kolaylıklar sağlamaktadır. Görüntüler üzerinde uygulanan çeşitli aritmetik yöntemlerle istenilen verilere ulaşma olanağı sağlamaktadır.

Bu çalışma da, ASTER SWIR görüntüleri üzerinde ana bileşenler dönüşümü ve dekorelasyon gerilmesi yöntemleri uygulanarak killeşme alanları ortaya konulmuştur. $\mathrm{Bu}$ yöntemlerle görüntüler üzerinde belirlenen alanlar, arazi çalışmaları sırasında sınırları belirlenmiş ve jeolojik harita üzerinde gösterilen killeşme alanları ile yüksek oranda örtüştüğü belirlenmiştir. Örtüşmeyen bölümlerin, arazinin çok sarp olmasına bağlı olarak uydu görüntüsünde yansımaların tam olarak alınmamasına ve uydu görüntüsünün mekânsal çözünürlüğünün düşük olmasına (30m) bağlı olduğu düşünülmektedir.

Uzaktan algılama yöntemleri ile yapılan bu çalışma sonucunda, bölgede belirlenebilecek diğer hidrotermal alterasyon alanlarının hem metalik 
maden arama faaliyetlerine hem de endüstriyel amaçlı kullanılabilecek kil alanlarının keşfinde ışı tutacağı düşünülmektedir.

\section{Teşekkür}

$\mathrm{Bu}$ araştırma Cumhuriyet Üniversitesi Bilimsel Araştırma ve Projeleri (CUBAP) tarafından M-613 nolu proje olarak desteklenmiştir.

\section{KAYNAKLAR}

[1]. Rowan, L. C., Schmidt, R. G., Mars, J. C., 2006. Distribution of hydrothermally altered rocks in the Reko Diq, Pakistan mineralized area based on spectral analysis of ASTER data. Remote Sensing of Environment, 104, 74-87

[2]. Bedini, E., Van Der Meer, F., Van, F., 2009. Ruitenbeek Use of HyMap imaging spectrometer data to map mineralogy in the Rodalquilar caldera, southeast Spain. Int. J. Remote. Sens., 30 (2), 327-348.

[3]. Gabr, S., Ghulam, A., Kusky, T., 2010. Detecting areas of high-potential gold mineralization using ASTER data. Ore Geol. Rev., 38, 59-69.

[4]. Pour, B.A., Hashim, M., Marghany, M., 2011. Using spectral mapping techniques on short wave infrared bands of ASTER remote sensing data for alteration mineral mapping in SE Iran. Int. J. Phys. Sci., 6 (4), 917-929.

[5]. Hunt, G.R.,1977. Spectral signatures of particulate minerals in the visible and near infrared Geophysics, 42, 501-513.

[6]. Abrams, M., 2000. The Advanced Spaceborne Thermal Emission and Reflection Radiometer (ASTER): data products for the high spatial resolution imager on NASA's Terra platform. Int. J. Remote. Sens., 21, 847-859.

[7]. Yamaguchi, Y., Kahle, A.B., Tsu, H., Kawakami,T., Pniel, M., 1998. Overview of Advanced Spaceborne Thermal Emission and Reflection Radiometer (ASTER). IEEE Transactions on Geoscience and Remote Sensing, 36, 1062-1071.

[8]. Abrams, M., Hook, S.J., 1995. Simulated ASTER data for geologic studies IEEE Trans. Geosci. Remote. Sens., 33 (3), 1995.

[9]. Fujisada, H., 1995. Design and performance of ASTER instrument. Proceedings of SPIE, 2583, 16-25.

[10].Crosta, A., De Souza Filho, C., Azevedo, F., Brodie, C., 2003. Targeting key alteration minerals in epithermal deposits in Patagonia, Argentina, using ASTER imagery and principal component analysis. Int. J. Remote sensing, 24 (21), 4233-4240.

[11].Di Tommaso, I., Rubinstein, N., 2007. Hydrothermal alteration mapping using ASTER data in the Infiernillo porphyry deposit, Argentina Ore Geol. Rev., 32, 275290.

[12].Ducart, D.F., Crosta, A.P., Filio, C.R.S., 2006. Alteration mineralogy at the Cerro La Mina epithermal prospect, Patagonia, Argentina: field mapping, short-wave infrared spectroscopy, and ASTER images. Econ. Geol., 101, 981-996.

[13].Rowan, L., Hook, S.J., Abrams, M.J., Mars, J.C., 2003. Mapping hydrothermally altered rocks at Cuprite, Nevada, using the Advanced Spaceborne thermal emission and reflection radiometer (ASTER), a new satellite-imaging system. Economic Geology and the Bulletin of the Society of Economic Geologists 98 (5), 1019-1027.

[14].Rowan, L.C., Mars, J.C., 2003. Lithologic mapping in the Mountain Pass, California area using Advanced Spaceborne Thermal Emission and Reflection Radiometer (ASTER) data. Remote Sensing of Environment, 84, 350-366.

[15].Rowan, L.C., Mars, J.C., Simpson, C.J., 2005. Lithologic mapping of the Mordar, NT, Australia, ultramafic complex by using Advanced Spaceborne Thermal Emission and reflection Radiometer (ASTER) data. Remote Sensing of Environment, 99, 105-126.

[16].Bedell, R.L., 2001. Geological mapping with ASTER satellite: new global satellite data that is a significant leap in remote sensing geologic and alteration mapping. Special Publication, Geo. Soc. of Nevada, 33, 329-334.

[17].Ninomiya,Y., FU, B., 2003. Extracting lithological information from ASTER multispectral thermal infrared data in the northeastern Pamirs. Xinjiang Geology, 21, $22-30$.

[18].Rockwell, B.W., Hofstra, A.H., 2008. Identification of quartz and carbonate minerals across northern Nevada using ASTER thermal infrared emissivity data implications for geologic mapping and mineral resource investigations in wellstudied and frontier areas Geosphere, 4 (1), 218-246.

[19].Efe, A., Gökce, A., 1999. Geology and fluid inclusion studies of the Maden Village (İmranl1-Sivas) $\mathrm{Pb}-\mathrm{Zn}$ deposits. Bulletin of 
faculty of engineering of Cumhuriyet University, Serie S- Earth Sciences, 16, 29-38

[20].Boztuğ, D., 2008. Petrogenesis of the Kosedag Pluton, Susehri-NE Sivas, East-Central Pontides, Turkey. Turkish Journal of Earth Science, 17(2), 241-262.

[21].Okay, A., Tüysüz, O., 1999. Tethyan sutures of northern Turkey. Geological Society, London, Special Publications, 156, 475-515.

[22].Eyuboglu, Y., 2010. Late Cretaceous high-K volcanism in the eastern Pontides orogenic belt, and its implications for the geodynamic evolution of NE Turkey. International Geology Review 52 (2-3), 142-186.

[23].Eyuboglu, Y., Santosh, M., Chung, S.L., 2011c. Crystal fractionation of adakitic magmas in the crust-mantle transition zone: petrology, geochemistry and $\mathrm{U}-\mathrm{Pb}$ zircon chronology of the Seme adakites, Eastern Pontides, NE Turkey. Lithos 121, 151-166.

[24].Eyuboglu, Y., Chung, S.L., Santosh, M., Dudas, F.O., Akaryali, E., 2011a. Transition from shoshonitic to adakitic magmatism in the Eastern Pontides, NE Turkey: implications for slab window melting. Gondwana Research 19, 413-429.

[25].Eyuboglu, Y., Santosh, M., Dudas, F.O., Chung, S.L., Akaryali, E., 2011b. Migrating magmatism in a continental arc: geodynamics of the Eastern Mediterranean revisited. Journal of Geodynamics 52, 2-15.

[26].Eyuboglu, Y., Santosh, M., Bektaş, O., Ayhan, S., 2011d. Arc magmatism as a window to plate kinematics and subduction polarity: example from the Eastern Pontides belt, NE Turkey. Geoscience Frontiers 2 (1), 49-56.

[27].Eyuboglu, Y., Santosh, M., Chung, S.L., 2011e. Petrochemistry and $\mathrm{U}-\mathrm{Pb}$ ages of adakitic intrusions from the Pulur massif (Eastern Pontides, NE Turkey): implications for slab roll-back and ridge subduction associated with Cenozoic convergent tectonics in eastern Mediterranean. Journal of Geology 119, 394-417.

[28].Eyuboglu, Y., Santosh, M., Yi, K., Bektaş, O., Kwon, S., 2013a. Discovery of Miocene adakitic dacite from the Eastern Pontides Belt and revised geodynamic model for the late Cenozoic Evolution of eastern Mediterranean region. Lithos 146-147, 218-232.

[29].Eyuboglu, Y., Santosh, M., Dudas, F.O., Akaryali, E., Chung, S.L., Akdag, K., Bektas, O.,2013b. The nature of transition from adakitic to non-adakitic magmatism in a slab- window setting: a synthesis from the eastern Pontides, NE Turkey. Geoscience Frontiers, 4, 353-375.

[30].Başıüyük, Z., 2006. Hydrothermal alteration mineralogy-petrography and geochemistry of Eocene volcanics: an example from quadrangle of Zara-İmranlı-Suşehri-Şerefiye (Northeast of Sivas, Central Eastern Anatolia, Turkey). PhD thesis, Sivas-Turkey, Cumhuriyet University, Institute of Science, 269pp.

[31].Iwasak1, A, Tonooka, H, 2005. Validation of a crosstalk correction algorithm 371 for ASTER/SIWR. IEEE Transactions on Geoscience and Remote Sensing, 43, 2747-2751.

[32].Gürsoy, Ö and Kaya, Ş., 2016. Detecting of Lithological Units by Using Terrestrial Spectral Data and Remote Sensing Image, Journal of the Indian Society of Remote Sensing, doi 10.1007/s12524-016-0586-1

[33].Gillespie, A. R., Kahle, A. B., Walker, R. E. 1986. Color enhancement of highly correlated images: I. Decorrelation and HIS contrast stretches. Remote Sensing of Environment, 20, 209- 235 .

[34].Gürsoy, Ö., Kaya, Ş., Çakir, Z., Tatar, O., Canbaz, O. 2017. Determining lateral offsets of rocks along the eastern part of the North Anatolian Fault Zone (Turkey) using spectral classification of satellite images and field measurements, Geomatics, Natural Hazards and Risk 10.1080/19475705.2017.1318794 